\title{
Molecular identification and evolutionary relationships between the subspecies of Musa by DNA barcodes
}

S. Dhivya', S. Ashutosh², I. Gowtham³, V. Baskar', A. Baala Harini', S. Mukunthakumar and R. Sathishkumar ${ }^{1 *}$

\begin{abstract}
Background: The banana (Musa sp., AAA) genome is constantly increasing due to high-frequency of somaclonal variations. Due to its large diversity, a conventional numerical and morphological based taxonomic identification of banana cultivars is laborious, difficult and often leads to subject of disagreements.

Results: Hence, in the present study, we used universal DNA barcode ITS2 region to identify and to find the genetic relationship between the cultivars and varieties of banana. Herein, a total of 16 banana cultivars were PCR amplified using ITS2 primer pair. In addition, 321 sequences which were retrieved from GenBank, USA, were used in this study. The sequences were then aligned using Clustal W and genetic distances were computed using MEGA V5.1. The study showed significant divergence between the intra- and inter-specific genetic distances in ITS2 region. BLAST1 and Distance methods proved that ITS2 DNA barcode region successfully identified and distinguished the cultivar and varieties of banana.

Conclusion: Thus, from the results of the present study, it is clear that ITS2 is not only an efficient DNA barcode to identify the banana species but also a potential candidate for enumerating the phylogenetic relationships between the subspecies and cultivars. This is the first comprehensive study to categorically distinguish the economically important banana subspecies and varieties using DNA barcodes and to understand its evolutionary relationship.
\end{abstract}

Keywords: Musa sp., Cultivar, Wild species, DNA barcode, Nucleotide diversity, Genetic relationship

\section{Background}

Banana and plantain belong to the family Musaceae and are cultivated throughout tropical and subtropical regions of the world [1]. This is an important crop next to rice, wheat and corn [2]. The edible Musa species and their hybrids and polyploids originated from the two main wild species of banana, viz., Musa acuminata Colla and M. balbisiana Colla, with A and B genomes, respectively [3]. The major cultivars belong to the subgroups of Cavendish (AAA), Lujugira (AAA),

\footnotetext{
* Correspondence: rsathish@buc.edu.in

'Plant Genetic Engineering Laboratory, Department of Biotechnology, Bharathiar University, Coimbatore 641046, India

Full list of author information is available at the end of the article
}

Figue Pomme (AAB), Plantain (AAB), Saba Bluggoe $(\mathrm{ABB})$ and Sucier (AA) [4]. Banana is a staple edible fruit crop with a good source of potassium and magnesium, which provides health benefits, such as, maintaining normal blood pressure and protecting against heart ailments [5]. The genome is continuously expanding due to the occurrence of high frequency somaclonal variation, increasing diversity, leading to quite often subject of disagreements [6].

There have been extensive discussions related to the identities of the progenitors of domesticated banana. $M$. acuminata and $M$. balbisiana have been proposed as wild parents of modern banana. There are four wild species, viz., M. acuminata (donor of A genome), $M$. 
balbisiana (donor of B genome), M. schizocarpa (donor of $\mathrm{S}$ genome) and $M$. textilis (donor of $\mathrm{T}$ genome), which have contributed to the gene pool of bananas. These wild species are extensively distributed in the subtropical and tropical regions of Asia. There are nine subspecies, such as, banksii, burmannica, burmannicoides, errans, malaccensis, microcarpa, siamea, truncata and zebrina are which are identified as offspring of $M$. acuminata $\mathrm{X} M$. balbisiana and these hybrids are found to exhibit several commonly occurring morphological characters. Though the species M. schizocarpa and M. textilis were endemic to Papua New Guinea, they do not show morphological diversification [7]. The species Musa nagensium remained unnoticed by botanists for quite long time and no collections were made more than a century from the habitat, viz., North-East India [8]. In addition, literature shows that the species $M$. cheesmanii N.W. simmonds was misidentified as $M$. nagensium and was provided with the photograph of the former. It was subsequently rediscovered and detailed description was provided by both $[9,10]$. Similarly, there was a misidentification of a species with AAA genome, which showed similarity to $\mathrm{ABB}$ genome [8]. The occurrence of genetic diversity has been satisfactorily documented in the pool of M. acuminata species by employing primers of highly repetitive sequences and tandem repeats by $[11,12]$. The total number of cultivars in bananas and plantains was estimated to be around 300-1000 and their nomenclature and descriptions are found to be highly ambiguous even within a country [13]. Cultivated bananas are found to differ markedly from their wild relatives due to multiplication through vegetative propagation, exhibiting a high level of morphological diversification [7]. Accordingly, later formulated classification schemes were found to be unambiguous and coherent and were accepted widely. Though the cultivated banana has socio-economic importance, genetic studies are found to be limited in this flora due to the occurrence of extensive polyploidy and parthenocarpy together with complexity associated with sample collection protocols. It is realized that correct identification of Musa cultivars is crucial for utilization of this crop species and also important for conservation of the genetic resources. Traditional methods to identify Musa cultivars relies more on morphological characters [14] which are often affected by environmental and developmental factors. Phenotypic classification and their usage in inferring genetic relationships among the different genotypes are still under debate [7]. Even employment of molecular markers, such as, Random Amplified Polymorphic DNA (RAPD) [15] did not provide sufficient discriminating capacity for classifying the nine genotypes of Musa [16]. Genomic in situ hybridization (GISH) is also not found to be suitable for high-throughput screening of large breeding populations [17]. It is pertinent to mention that DNA markers were employed for identifying dwarf Cavendish banana derived from micropropagation [18]. DNA fingerprinting methodologies are found to be useful in detecting the relationship between parental genotypes with progeny populations [19]. Plastid subtype identity (PS-ID) through sequence analysis was carried out to show the possible maternal relationship among Musa sp. [20]. Polymerase chain reaction-restriction fragment length polymorphism (PCRRFLP) markers of ribosomal internal transcribed spacers (ITS) were used to determine the Musa genome and hybrids at the nursery stage [21]. With the current status of research in this area of foolproof identification of Musa species and cultivars, a simple and accurate method is highly required for determining the genetic variation between the different cultivars of Musa species.

DNA barcoding is a recent technique that uses short and standardized DNA fragments to discriminate the specimens at the species level [22-24]. Many disputed species have been correctly identified by employing DNA barcoding [25]. Herbal products have also been authenticated through DNA barcodes [26, 27]. A few studies have reported the applicability of DNA barcodes even for identifying herbarium samples [28], intra-specific ecotypes [29] and ornamental species for horticultural industries [30]. Hence, DNA barcoding has become an efficient tool for identification with discriminating power at the species level [23]. The chloroplast DNA sequences, such as, matK, $r b c L$, $p s b A-t r n H$, and atpF-atpH and internal transcribe spacer (ITS) region of nuclear ribosomal DNA have been proposed as potential plant barcodes [31]. The internal transcribed spacer 2 (ITS2) is located between the ribosomal $5.8 \mathrm{~S}$ and $28 \mathrm{~S}$, which is actively involved in the regulation of the transcription of active ribosomal subunits and it is essential for pre-rRNA processing [32]. By employing the conserved regions, it is easy to design a universal primer, PCR amplification and DNA sequencing of amplicons which will reveal the variability that can be used to distinguish the closely related species. Due to this universality, in the current scenario, ITS2 has been considered to be a standard barcode for authenticating different medicinal plants [33-36]. Recently DNA barcoding has been appropriately employed in clear identification of the different varieties of plants, imported teas [37] and small millet land races [38]. In the present study, DNA barcoding analysis was performed for the banana cultivars and wild Musa accessions using the internal transcribed spacer region ITS2 for a better understanding of the origin and domestication of cultivated banana and to clear the confusions that exist in the nomenclature and varietal synonyms.

\section{Results}

PCR success rate and DNA sequencing

The amplification and sequence success rate of the ITS2 sequences from sampled specimens of Musa sp. was 
found to be $100 \%$. The lengths of the ITS 2 sequences used for the analyses were in the range of $325-375 \mathrm{bp}$, with an average of $345 \mathrm{bp}$. The mean GC content was $60.3 \%$, with a range of $58.3-69.0 \%$.

\section{Genetic diversity}

Genetic divergences were estimated using six metrics, such as, average inter-specific distance, the minimum inter-specific distance, theta prime, average intra-specific distance, coalescent depth and theta. The region ITS2 exhibits significant divergences at the inter-species level (Table 1) at the level of cultivars and varieties. At the intra-specific level, relatively lower divergences were observed for all the corresponding metrics.

\section{Assessment of barcoding gap}

inter-specific versus intra-specific divergence was analyzed by examining the distribution of genetic distance at a scale of 0.008 distance units. Observations showed that there was only a slight overlap in inter and intraspecific variation (Fig. 1). The inter-specific distance was found to be in the range of $0.002-0.184$ equaled 0.002 for only $0.26 \%$ and the proportion of inter-specific genetic distance $<0.135$ was about $8.33 \%$. The intra-specific distance ranged from 0.000 to 0.135 , and most Musa species with more than two samples in our study had a unique sequence $(58.93 \%)$ in the ITS2 region. The results indicated the existence of significantly evident barcoding gap between inter and intra-specific divergence thus indicating that ITS2 could provide a useful region to identify and authenticate different Musa species.

\section{Efficacy of ITS2 for authentication}

ITS2 showed 97.7 and $95.8 \%$ identification success rates at the species level for the 321 analysed samples of Musa using BLAST1 and nearest genetic distance, respectively. Nearly 15 cultivar and wild species were identified that are shown in Table 2. Thus, the ITS2 region exhibited high identification efficiency for Musa sp.

\section{Sequence analysis and species discrimination}

ITS2 sequences were collected and evaluated using MEGA (Fig. 2). As a result, over $95.6 \%$ of species had

Table 1 Genetic distance determination using ITS2 region for 277 samples of 46 Musa cultivars

\begin{tabular}{ll}
\hline Measurement & Kimura 2- parameters (K2P) value \\
\hline All inter-specific distance & $0.194 \pm 0.076$ \\
Theta prime & $0.187 \pm 0.064$ \\
The minimum inter-specific distances & $0.122 \pm 0.046$ \\
All intra-specific distances & $0.035 \pm 0.006$ \\
Theta & $0.081 \pm 0.004$ \\
Coalescent depth & $0.070 \pm 0.018$ \\
\hline
\end{tabular}

larger inter-than intra-specific diversity; therefore, there were relatively clear species boundaries for ITS2 sequences. Only two species which were found to fall under the exception category, viz., M. schizocarpa and $M$. acuminata $\mathrm{x} M$. textilis had very less variability of about $0.035 \%$. ITS2 region showed higher polymorphic sites representing higher genetic diversity in between subspecies and cultivars of Musa. Unique haplotypes of Musa species and subspecies were identified by using restriction enzymes, such as, MseI, PstI and AvaII, respectively and are shown in Table 3.

\section{Nucleotide polymorphism and neutrality tests}

DNA polymorphism analysis showed rich genomic variations in Musa accessions, with the total number of polymorphic sites being 112 in cultivated bananas in A genome and 33 in $B$ genome. Nucleotide diversity $(\pi$ and $\theta$ ) for all the cultivated and wild Musa accessions were estimated for silent, non-synonymous and total sites independently. Summaries of nucleotide diversity data for two ITS2 regions are given in Table 4. Reduced levels of polymorphism emerged as a general property of cultivated bananas as compared to their wild progenitors. It shows that subspecies has slightly higher level of nucleotide diversity than wild and cultivated species. Thus, these findings suggest that the cultivars would not have undergone any severe genetic bottleneck during the initial domestication process. The triploid genome AAA and $\mathrm{AAB}$ groups also hold high levels of nucleotide diversity, representing the historical population sizes are large. The $\mathrm{ABB}$ genome of cultivated banana shows higher nucleotide diversity than that of M. balbisiana (Table 4). We found that nucleotide diversity at nonsynonymous sites ITS2 region was reduced in the A genome of wild species represented as shown in Table 4. No polymorphic sites were observed within the cultivar and subspecies. However, it was found that the genetic diversity of the AAA genome was 4-6 and folds higher than A genome cultivars. Additionally, the patterns of nucleotide variations in ITS2 region was examined for deviation from neutral equilibrium evolution using Tajima's neutrality (D) test. Thus, the observations of the present study showed no significant departure from the neutral model.

\section{Phylogenetic analysis}

The molecular classification of Musa species is based on DNA based profiling $[39,40]$. To analyze the phylogenetic relationship of Musa cultivars with wild species, nearly 103 species representing 60 cultivars, 5 wild species and 9 subspecies were studied using the Maximum Likelihood (ML) method as depicted in Fig. 3. Among 98 sequences, 31 sequences were taken as representative group for the comparative analysis for cultivar and wild 


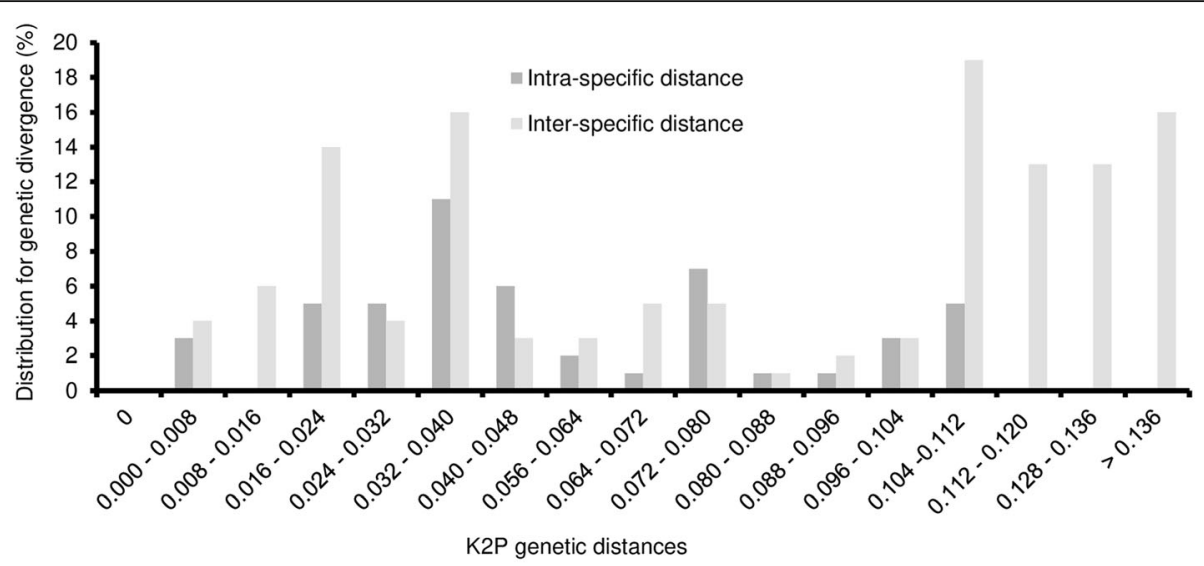

Fig. 1 The Relative distribution of inter-specific divergence between congeneric Musa species and intra-specific variation $(P<0.001)$ by MEGAX

samples from the laboratory source. Sequences for the subspecies and hybrids were obtained from the GenBank and the sequence of the species Ensete ventricosum was treated as an outgroup. The phylogenetic tree (Fig. 3) consists of three main clades, viz., A, B, and C. In clade A, cultivar red banana was found to be evolutionarily related to wild species, viz., $M$. balbisiana, $M$. textilis and $M$. schizocarpa. Further the cultivar red banana was found to be closer to subspecies $M$. acuminata subsp. truncata. The clade B consisted of 5 cultivars, viz., Pisang lilin, M. acuminata var. flava isolate, chemmatti, grandnain and nadan and all those cultivars were found to be closely related to the banana subspecies, viz., $M$. acuminata subsp. microcarpa and M. banksii. Among the 4 cultivars belonging to clade C, 3 cultivars, viz., Njalipoovan, Matti and Kunnan, were found to be closely related to wild species of banana, viz., M. acuminata, M. balbisiana and M. accuminatavar. Burmanicoides, respectively.

From (Fig. 4), it could be inferred that the clade I was the most complex with 50 cultivars belonging to the wild species Musa balbisiana. Six banana species, viz., $M$. violascens, M. splendida, M. hirta, M. campestris, M. gracilis and M. salaccensis, were grouped into the same clade I. The species $M$. beccarii, and its variety were assigned to clade II. The species $M$. peekelii and $M$. ingens are distinct from the species M. maclayi, which exhibited high similarity index and were placed in the clade III. The species M. monticola and M. barioensis were placed in clade IV due to their closeness. Four other species, viz., M. textilis, M. jackeyi, M. peekelii and M. troglodytarum were grouped under clade $\mathrm{V}$ and the species $M$. coccinea and $M$. lutea were placed in the neighboring section of clade $\mathrm{V}$. The following species, viz., $M$. rosea, $M$. serpentina, $M$. rubra, $M$. laterita, $M$. textilis were found to share same allelic profiles with the wild species M. balbisiana and M. accuminata. The following two species, viz., M. zaifei, $M$. siamensis and also the different varieties collected by us, viz., Robusta, Red banana, cultivar Pisang lilin, Nadan, Chemmatii and Grandnain shared a comparable allelic profile with the wild species - M. accuminata. Yet another group of seven species, viz., M. mannii, M. ornata, M. yunnanensis, M. tonkinensis, M. itinerans, $M$. formosana and $M$. viridis were grouped under the same section and exhibited closer relationship with the wild species $M$. balbisana. A single cultivar was separated from the wild species $M$. balbisana and was elevated as a species, viz., $M$. nagensium. Clade II consisted of 5 taxon which included four cultivars, viz., Njalipoovan, Matti, Kunnan and wild M. accuminata var burmanicoides $A A$, shared significant genetic relationship with wild species of $M$. accuminata. Clade III consisted of a single taxon - M. basjoo, which is found to be distinct from the wild species, viz., M. accuminata and M. balbisiana as shown in Fig. 4.

\section{Data analysis using restriction enzymes}

Results of the present study showed that the restriction enzymes - MseI and AvaII, provided the best discriminatory power to differentiate the haploids of Musa species using ITS2 sequences. MseI showed single restriction site for 11 genomes of wild and cultivars of banana. A second group of 3 genomes showed two restriction sites at different locations on the genome. AvalI showed one, two and three restriction sites in the II group of 3 genomes, respectively.

\section{Discussion}

A common problem for banana researchers and horticulturists in Southeast Asia is the presence of numerous cultivar names and synonyms in different languages in the region. Having a better knowledge of synonyms may promote banana trade and commerce. A rapid and reliable method for species and cultivar 
Table 2 Identification efficiency for ITS2 using BLAST1 and DISTANCE methods

\begin{tabular}{|c|c|c|c|c|}
\hline Sample Name & Sample Identified & $\begin{array}{l}\text { Methods of } \\
\text { Identification }\end{array}$ & $\begin{array}{l}\text { Correct Identification } \\
(\%)\end{array}$ & $\begin{array}{l}\text { Ambiguous Identification } \\
(\%)\end{array}$ \\
\hline \multirow[t]{2}{*}{ Robusta } & \multirow[t]{2}{*}{ M. aurantiaca } & BLAST1 & 97 & 3 \\
\hline & & DISTANCE & 97.06 & 2.94 \\
\hline \multirow[t]{2}{*}{ Nadan } & \multirow[t]{2}{*}{ M. banksii } & BLAST1 & 96 & 3 \\
\hline & & DISTANCE & 96.04 & 3.06 \\
\hline \multirow{2}{*}{$\begin{array}{l}\text { Wild Musa } \\
\text { accuminatavar.burmanicoides } A A\end{array}$} & \multirow[t]{2}{*}{ Musa $A B B$} & BLAST1 & 99 & 1 \\
\hline & & DISTANCE & 99.7 & 0.3 \\
\hline \multirow[t]{2}{*}{ Wild Musa accuminata AA } & \multirow{2}{*}{$\begin{array}{l}\text { M. acuminata subsp. } \\
\text { malaccensis }\end{array}$} & BLAST1 & 99 & 1 \\
\hline & & DISTANCE & 99.37 & 0.63 \\
\hline \multirow[t]{2}{*}{ Njalipoovan $A B$} & \multirow{2}{*}{$\begin{array}{l}\text { Musa acuminata subsp. } \\
\text { malaccensis }\end{array}$} & BLAST1 & 98 & 2 \\
\hline & & DISTANCE & 98.45 & 1.55 \\
\hline \multirow[t]{2}{*}{ Wild Musa balbisiana BB } & \multirow[t]{2}{*}{ Musa laterita } & BLAST1 & 98 & 2 \\
\hline & & DISTANCE & 98.41 & 1.59 \\
\hline \multirow[t]{2}{*}{ Wild Musa balbisiana BB } & \multirow[t]{2}{*}{ Musa balbisiana } & BLAST1 & 98 & 2 \\
\hline & & DISTANCE & 97.68 & 2.32 \\
\hline \multirow[t]{2}{*}{ Wild Musa accuminata } & \multirow[t]{2}{*}{ Musa accuminata } & BLAST1 & 96 & 4 \\
\hline & & DISTANCE & 95.81 & 4.19 \\
\hline \multirow[t]{2}{*}{ Cultivar Pisang lilin } & \multirow[t]{2}{*}{ Musa acuminata var. zebrina } & BLAST1 & 99 & 1 \\
\hline & & DISTANCE & 98.9 & 1.1 \\
\hline \multirow[t]{2}{*}{ Cultivar Chemmatti - AA } & \multirow[t]{2}{*}{ Musa campestris } & BLAST1 & 97 & 3 \\
\hline & & DISTANCE & 96.7 & 3.3 \\
\hline \multirow[t]{2}{*}{ Wild Musa accuminata } & \multirow[t]{2}{*}{ Musa laterita } & BLAST1 & 95 & 5 \\
\hline & & DISTANCE & 95.15 & 4.85 \\
\hline \multirow[t]{2}{*}{ Cultivar Kunnan BA } & \multirow{2}{*}{$\begin{array}{l}\text { Musa acuminata subsp. } \\
\text { malaccensis }\end{array}$} & BLAST1 & 99 & 1 \\
\hline & & DISTANCE & 99 & 1 \\
\hline \multirow[t]{2}{*}{ Grandnain } & \multirow[t]{2}{*}{ Musa acuminata } & BLAST1 & 94 & 6 \\
\hline & & DISTANCE & 94.11 & 5.89 \\
\hline \multirow[t]{2}{*}{ Cultivar Matti AA } & \multirow[t]{2}{*}{ Musa acuminata var. zebrina } & BLAST1 & 99 & 1 \\
\hline & & DISTANCE & 98.21 & 1.79 \\
\hline \multirow[t]{2}{*}{ Red Banana } & \multirow{2}{*}{$\begin{array}{l}\text { Musa acuminata subsp. } \\
\text { malaccensis }\end{array}$} & BLAST1 & 99 & 1 \\
\hline & & DISTANCE & 99.1 & 0.9 \\
\hline
\end{tabular}

recognition is vital to certify the fruits and plantlets of Musa sp. and to preserve banana germplasm resources [9]. To our knowledge, this is the first report wherein DNA barcoding has been employed in the identification of different species and cultivars of Musa using a large sample size. An ideal DNA barcode should include higher inter-specific but low intra-specific divergence to discriminate different species [24] which has been shown in many earlier studies for various species and cultivars of Colletotrichum isolates [41], fig [42], grapevine [43], and pineapple [44]. In the present study, ITS2 was found to possess a sufficient variable region between the different species and cultivars for the determination of genetic divergence with high discriminatory ability.
Morphological characters were found to resolve $M$. acuminata populations that were cultivated only at high land regions. In contrast, low land banana populations are known to show overlapping and no distinguishing pattern of phenotypic traits were observed [45]. PCR-RFLP of the ITS region using RsaI restriction endonuclease was used on 68 banana accessions, which showed consistent and distinguishing polymorphic banding of DNA patterns between the wild species and cultivars of $M$. acuminata [40, 46]. Similarly, acceptable structural diversity and molecular phylogeny were observed when an ITS1-5.8S-ITS2 region was used for the species of Musaceae [47]. Based on the results of the present study, we propose that ITS2 can be an ideal DNA barcode candidate for 


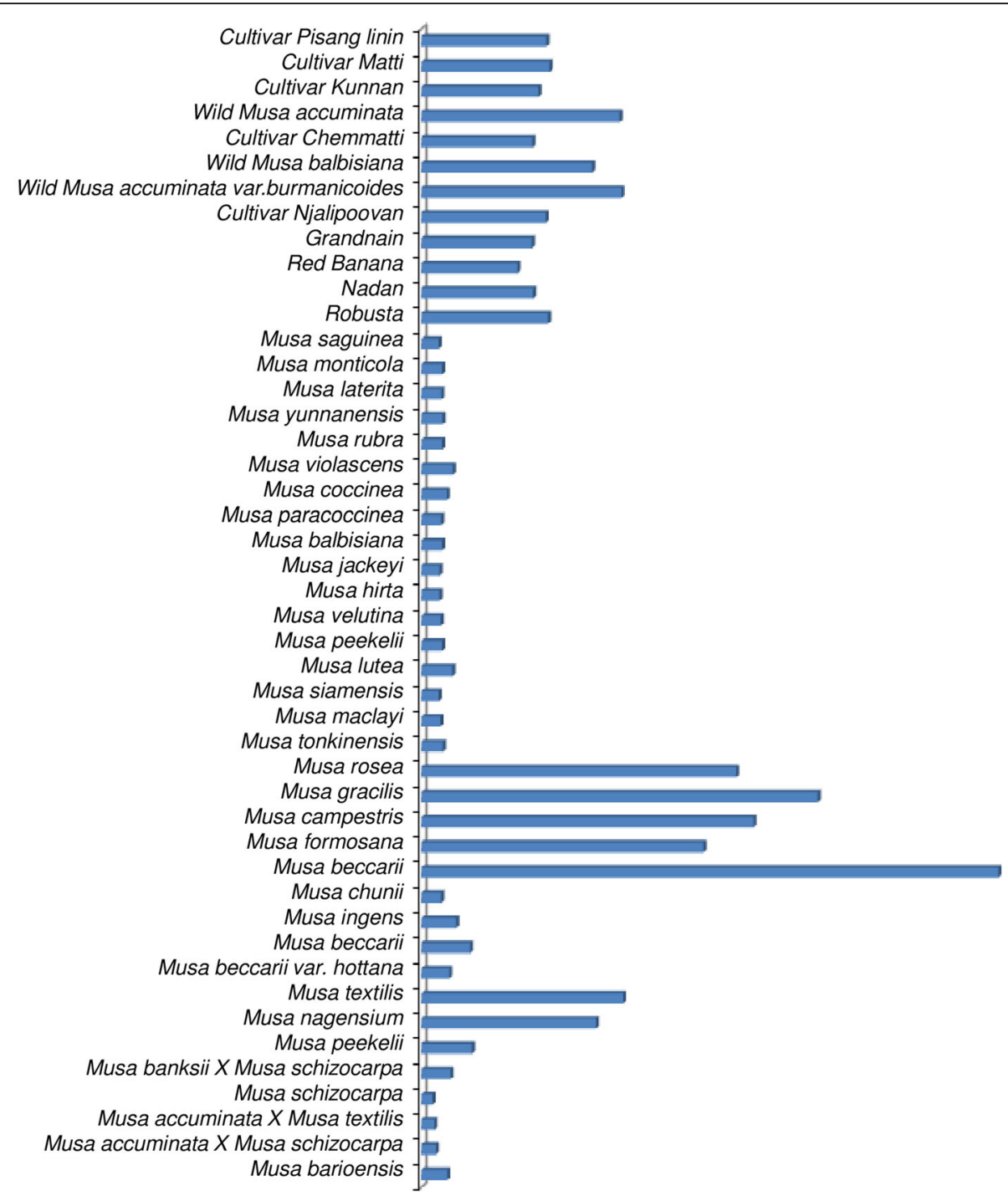

Fig. 2 The heterogeneity of individual taxa by ITS2 based on 46 Musa subspecies by MEGAX. The left side shows the complete list of Musa species used in this study. The right side depicts heterogeneity between and within species, where the values are calculated by using a similarity matrix for biomarker ITS2 with different OTUs (Operational Taxonomic Units)

Musa sp. However, it is pertinent to mention that the phylogeny of the members of the Musaceae remains still controversial. To cite a few cases, it is known that the taxonomic position of the species $M$. beccarii remains uncertain and the species $M$. ingens is still not documented unambiguously in taxonomic attributes [48]. Hence, the taxonomic assignment of cultivars of Musa based on the ITS2 and its discriminating power in firmly assigning the identification and nomenclature of the members of the Musaceae might prove to be conclusive.

The phylogenetic tree shows three clades, viz., A, B and C. Clade A is found to contain two clusters. The B genome of $M$. balbsiana seems to be closer to $M$. acuminata subsp. Siamea, whereas subsp. burmannica and burmannicoides form distinct and separate groups (Fig. 3). Based on BLAST1 and distance-based identification methods the cultivars - red banana and robusta of AAA genome was found to be closer to subspecies $M$. acuminata subsp. truncata. The cultivar red banana showed 99 and $99.1 \%$ as Musa acuminata subsp. malaccensis, on the basis of the abovementioned two methodologies, respectively.

In the clade $\mathrm{B}$, the species $M$. textilis, M. banksii $x$ Musa schizocarpa and M. schizocarpa are grouped under the same cluster. The hybrid M. banksii x Musa schizocarpa was closely related to the wild species $M$. schizocarpa. The cultivar cluster - pisang lilin is inferred to be closely related to $M$. acuminata subsp. microcarpa and the subspecies M. banksii. Based on the BLAST1 
Table 3 Haplotypes discrimination of ITS2 sequence using Restriction Enzyme Mapping

\begin{tabular}{llll}
\hline Species Name & Msel & Pstl & Avall \\
\hline Robusta & 363 & - & 293,324 \\
Nadan & 63 & - & 333,353 \\
Wild Musa accuminata var.burmanicoides AA & 50 & - & $32,119,139$ \\
Wild Musa accuminata AA & 28 & - & 84,97 \\
Njalipoovan AB & - & - & 35,66 \\
Wild Musa balbisiana BB & 5444 & & 354,374 \\
Wild Musa balbisiana BB & 5 & - & 354,374 \\
Wild Musa accuminata & 11 & - & 111 \\
Cultivar Pisang & 370 & - & 280,300 \\
Cultivar Chemmatti - AA & 54,411 & - & $321,341,372$ \\
Wild Musa accuminata & 28 & - & 84,97 \\
Cultivar Kunnan BA & 148 & - & $186,217,237$ \\
Grandnain & 107,116 & - \\
Cultivar Matti AA & 77 & 353 & - \\
Red Banana & & 283,314 \\
\hline
\end{tabular}

and distance based identification methods, the A genome of cultivar Pisang lilin was found to show 99 and 98.9\% similarity with Musa acuminata var. zebrina, respectively. The cultivar chemmatti $A A$ and Grandnain were found to be closely related and identified as Musa campestris and Musa acuminata with a similarity of 97 and $94 \%$, respectively. The cultivar nadan showed 96\% similarity with subspecies $M$. banksii. In the clade C, the wild species of banana M. balbisiana and M. acuminata and the subspecies $M$. accuminata var. burmanicoides $A A$ and the cultivar Njalipoovan and Matti of A genome were grouped under the same cluster. The cultivar Njalipoovan and Matti were identified as Musa acuminata subsp. malaccensis and M. acuminata var. Zebrine, respectively with high degree of certainity with the employment of barcoding methodologies. The species $M$ balbisiana isolate LHP3 was grouped as Musa $A B B$. Thus, the results and inferences of the present study pinpoint that cultivars used in the present study might have originated from the wild species $M$. acuminata and its subspecies, respectively and Ensete ventricosum as an outgroup.

\section{Conclusion}

In summary, our study demonstrated that ITS2 is an ideal DNA barcode (a) to identify Musa subspecies or cultivars and (b) for the reconstruction of the phylogeny of the genus Musa. However, more Musa species need to be included in the future to verify whether these findings hold good even if closely related taxa are newly included. In conclusion, DNA barcoding offered highly useful genetic information about very complex Musa species, which will be very useful for germplasm management and in resource protection.

\section{Methods \\ Plant materials}

From GenBank, 321 sequences were obtained, out of which 256 sequences belong to 46 species/subspecies and 65 sequences to wild isolates. We sequenced 28 Musa samples out of which 12 species were from the Western Ghats of India. Those sequences were submitted to GenBank and their accession numbers are given in Table 5 and their images are shown in supplementary Fig. 1. Nearly 46 annotated species and subspecies of GenBank sequences were employed in the present study and are shown in supplementary Table 1.

\section{DNA extraction, amplification and sequencing}

Fresh, young leaves of sampled specimens were collected and genomic DNA was isolated by following [49]. The ITS2 region was amplified using the following pair of F-5' ATGCGATAC TTGGTGTGAAT 3' and R-5' TCCTCC GCTTATTGATATGC 3' of universal primers [50, 51]. Primers were synthesized by Integrated DNA Technologies, USA. PCR was carried out in $25 \mu \mathrm{L}$ volume contain-

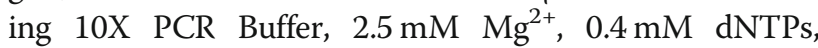
$0.5 \mu \mathrm{M}$ of each primer, $1 \mathrm{U}$ Taq DNA polymerase (GeneI, India), and $30 \mathrm{ng}$ genomic DNA template. The amplification was performed in a Gradient Master Cycler (Eppendorf, Germany) with a PCR program: $94^{\circ} \mathrm{C}$ for $4 \mathrm{~min}$, followed by 35 cycles of $94{ }^{\circ} \mathrm{C}$ for $45 \mathrm{~s}, 56^{\circ} \mathrm{C}$ for $45 \mathrm{~s}, 72^{\circ} \mathrm{C}$ for $1.5 \mathrm{~min}$, and a final extension at $72{ }^{\circ} \mathrm{C}$ for $10 \mathrm{~min}$. The PCR products were sequenced by the ABI-3130 Genetic Analyzer (Bioserve, India). 
Table 4 Summary of nucleotide diversity and neutrality test statistics for ITS2

\begin{tabular}{llllllll}
\hline Taxonomic groups & Genome & Ha & S & Ps & $\Theta$ & D \\
\hline A genome & AAA & 39 & 283 & 0.632 & 0.531 & 0.531 & -0.18425 \\
& AAB & 8 & 75 & 0.115 & 0.076 & 0.074 & 0 \\
& AA Wild Species & 4 & 16 & 0.089 & 0.049 & 0.049 & 0.123 \\
& A Subspecies & 13 & 132 & 0.589 & 0.189 & 0.73 & -0.833 \\
& A Cultivar & 48 & 132 & 0.663 & 0.149 & 0.113 & -0.845 \\
B genome & Over All & 112 & 638 & 0.417 & 0.198 & 0.299 & -0.347 \\
& BB & 6 & 23 & 0.125 & 0.054 & 0.052 & -0.235 \\
& ABB & 27 & 233 & 0.373 & 0.125 & 0.120 & -0.5 \\
\hline
\end{tabular}

\section{Sequence and genetic relationship analysis}

The original sequences were analyzed using MEGA [51], the ITS2 sequences were subjected to Hidden Markov Model analysis to remove the conserved $5.8 \mathrm{~S}$ and $28 \mathrm{~S}$ DNA sequences [24]. The ITS2 sequence was aligned using Clustal W [52] and the genetic distance computed using MEGA X 5.1 according to the Kimura 2- parameter (K2P) model [51]. The average intra-specific distance, the minimum intraspecific distance and theta prime were used to represent inter-specific divergences using the K2P model $[23,33]$. The average intra-specific distance, coalescent depth and theta were calculated to evaluate the intraspecific variation [24]. The distributions of inter- versus intra-specific variability were compared using the DNA barcoding gaps [52]. Wilcoxon two-sample tests were performed as indicated previously [53]. Two methods for species identification including BLAST1 and the nearest distance method were used to evaluate the species authentication efficacy [54-56]. ITS2 sequences of Musa species in this study were used as query sequences. BLAST program (http://blast.ncbi.nlm.nih.gov/ Blast.cgi) was used to search for the reference database for each query sequence. In the nearest distance method, correct identification means that the hit in our database based on the smallest genetic distance is from the same species as that of the query. Ambiguous identification means that several hits from our database were found to have the same smallest genetic distance to the query sequence. Incorrect identification means that the hit based on the smallest genetic is not from the expected species [33]. The discriminatory power of ITS2 sequences was calculated using MEGA X.

To understand the wild parents of cultivated bananas, the Maximum likelihood (ML) method for phylogenetic inference was carried out in MEGA version 5.1 [52], using Kimura's 2- parameter distances [57]. Gaps were treated as missing data and bootstrap values for the ML trees were obtained from 1000 replicates. We evaluated

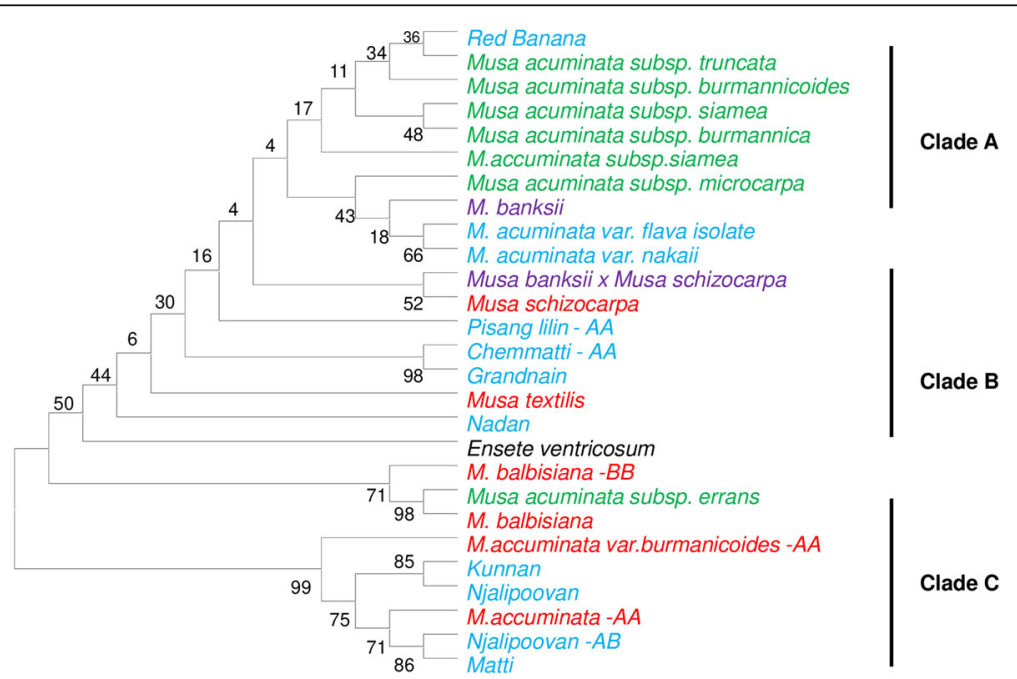

Fig. 3 Maximum Likelihood (ML) tree for Musa accessions using the ITS2 region. Numbers are bootstrap percentage above 50\%. Capital letters following each accession name indicate the previously- recognized genome composition of the cultivar. The appearance of an accession more than once represents a distinct sequence cloned from the same cultivar. Red indicates wild species, green indicates subspecies and blue indicates cultivar 


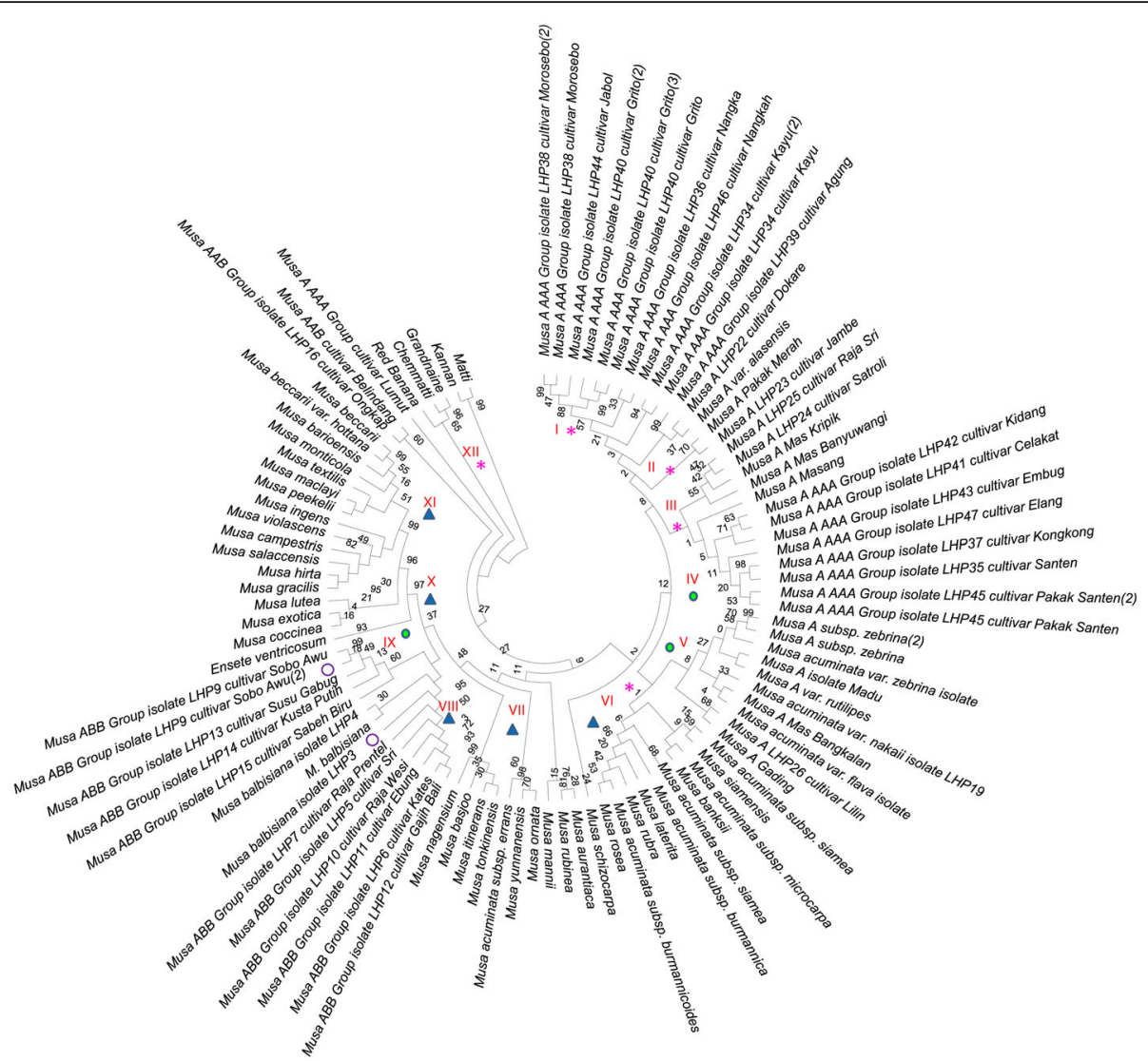

Fig. 4 Maximum Likelihood (ML) tree based on ITS2 sequences for Musa species. Numbers above branches indicate bootstrap support (BS $\geq 50$ ) values. $\triangle$ - Wild and subspecies of Musa, * - Cultivar species of Musa, - Varieties of Musa,

Table 5 Number of chromosomes and ploidy levels of Musa species /Cultivar names and its GenBank Accessions

\begin{tabular}{llllll}
\hline S.NO & Accession Number & Species/ Cultivar Names & Number of Chromosomes & Ploidy & Cultivated Clones/ Subspecies \\
\hline 1 & KY710751 & cultivar Nadan & 33 & $3 n=3 x$ & Cultivated clones \\
2 & KY710752 & Musa acuminata subsp. burmannicoides & 22 & $2 n=2 x$ & Subspecies \\
3 & KY710753 & Musa acuminata & 22 & $2 n=2 x$ & Wild Species \\
4 & KY710754 & cultivar Njalipoovan & 33 & $3 n=3 x$ & Cultivated Clones \\
5 & KY710755 & Musa balbisiana & 22 & $2 n=2 x$ & Wild Species \\
6 & KY710756 & Musa acuminata & 22 & $2 n=2 x$ & Wild Species \\
7 & KY710757 & Cultivar Pisang lilin & 33 & $3 n=3 x$ & Cultivated Clones \\
8 & KY710758 & cultivar Chemmatti & 33 & $3 n=3 x$ & Cultivated Clones \\
9 & KY710759 & Musa acuminata & 33 & $3 n=3 x$ & Wild Species \\
10 & KY710760 & cultivar Kunnan & 33 & $3 n=3 x$ & Cultivated Clones \\
11 & KY710761 & cultivar Njalipoovan & 33 & $3 n=3 x$ & Cultivated Clones \\
12 & KY710762 & cultivar Grandnain & 33 & $3 n=3 x$ & Cultivated Clones \\
13 & KY710763 & cultivar Matti & 33 & $3 n=3 x$ & Cultivated Clones \\
14 & KY710764 & Red Dacca (Red Banana) & 33 & $3 n=3 x$ & Cultivated Clones \\
15 & KY710765 & Robusta & 33 & $3 n=3 x$ & Cultivated Clones \\
\hline
\end{tabular}


overall nucleotide diversity and also for AAA, AAB, AA, Wild species, subspecies, and cultivar respectively. Genetic analysis of sequence polymorphism was performed using MEGA $X$. The number of segregating sites (S), the number of haplotypes $(\mathrm{H})$, Tajima's D was determined [58]. In addition, we surveyed nucleotide diversity ( $\pi$ ) [59] and theta $(\theta)$ [60] for total, silent and nonsynonymous sites independently, whereas insertion/deletions (indels) were not included in this analysis.

\section{Data analysis using restriction enzymes}

ITS2 sequence data of 15 specimens were aligned and restriction patterns were predicted as shown in Table 3 using NEB cutter. Restriction fragments were predicted and compared for choosing the best discriminatory enzymes for haplotypes discrimination.

\section{Supplementary information}

Supplementary information accompanies this paper at https://doi.org/10. 1186/s12864-020-07036-5.

Additional file 1: Supplementary Table 1. Number of taxa used in this study.

Additional file 2: Figure S1. Different varieties of banana used in this study.

\section{Abbreviations}

ITS: Internal transcribed spacer; matK: maturase K; MEGA: Molecular Evolutionary Genetics Analysis; ML: Maximum Likelihood; K2P: Kimura 2parameter

\section{Acknowledgments}

The authors are thankful to Bharathiar University for the research facility. SR is thankful to UGC - SAP, and DST-FIST. DS is grateful to University Grant Commission (UGC) Women's Post-Doctoral Research Award (PDFWM -2015-17TAM-34021)

\section{Authors' contributions}

All authors approved the study. DS conceived the idea and designed the experiments. GI, BV, and MS collected the samples. BA and Gl performed the experiments. DS analyzed the data and wrote the manuscript. SR finalized the manuscript. DS, GI, BV, AS, and SR have read and approved the final manuscript.

\section{Funding}

This research is supported by UGC-SAP, DST-FIST and UGC Women's PostDoctoral Research Award (PDFWM -2015-17-TAM-34021).

\section{Availability of data and materials}

All the data analyzed in this study are included in this article and its supplementary information files with accession numbers at the NCBI database (https://www.ncbi.nlm.nih.gov/).

\section{Ethics approval and consent to participate}

Not applicable.

\section{Consent for publication}

Not applicable.

\section{Competing interests}

The authors declare that they have no conflicts of interests (financial/ nonfinancial) concerning this article.

\section{Author details}

'Plant Genetic Engineering Laboratory, Department of Biotechnology, Bharathiar University, Coimbatore 641046, India. ${ }^{2}$ Technologico de Monterrey, Centre of Bioengineering, Epigmenio Gonzalez \#500, Fracc. San Pablo, Campus Queretaro, Santiago de Querétaro, Queretaro, Mexico. ${ }^{3}$ Plant Biofarming Laboratory, DRDO-BU Centre for Life Sciences, Bharathiar University, Coimbatore 641046, India. ${ }^{4}$ Biotechnology and Bioinformatics Division, Jawaharlal Nehru Tropical Botanic Garden \& Research Institute, Palode, Thiruvananthapuram, Kerala 695 562, India.

Received: 31 January 2020 Accepted: 30 August 2020

Published online: 24 September 2020

\section{References}

1. Li LF, Wang HY, Zhang C, Wang XF, Shi FX, Chen WN, et al. Origins and domestication of cultivated Banana inferred from chloroplast and nuclear genes. PLoS One. 2013;18:e80502.

2. Perrier $\mathrm{X}$, Langhe $\mathrm{E}$, Donohue $\mathrm{M}$, Lentfer $\mathrm{C}$, Vrydaghs L, Bakry $\mathrm{F}$, et al. Multidisciplinary perspectives on banana (Musa spp.) domestication. PNAS. 2011:108:113-8.

3. Opara UL, Jacobson D, Al-Saady NA. Analysis of genetic diversity in banana cultivars (Musa cvs.) from the south of Oman using AFLP markers and classification by phylogenetic, hierarchical clustering and principal component analyses. J Zhejiang Univ Sci B Hangzhou. 2010:11:332-41.

4. Aurore G, Parfait B, Fahrasmane L. Bananas, raw materials for making processed food products. Trends Food Sci Technol. 2009;20:78-91.

5. Sampath KKP, Bhowmik D, Umadevi S, Duraivel S. Traditional and medicinal uses of Banana. J Pharmacogn Phytochem. 2012;1:51-63.

6. Ploetz RC. Fusarium wilt of Banana. Phytopathology. 2015;105:1512-21.

7. Simmonds NW, Weatherup STC. Numerical taxonomy of the wild bananas (Musa). New Phytol. 1990;115:567-71.

8. Alfred J, Sreejith PE, Ashfak AO, Sabu M. Regarding the identity, rediscovery and taxonomic history of Musa nagensium (Musaceae) from India. Rheedea. 2014;24:5-11.

9. Uma S, Sathiamoorthy S, Durai S. Banana Indian Genetic Resources and Catalogue. Tiruchirapalli: National Research Center for Banana (NRCB) India. National Research Centre for Banana (NRCB); 2005. p. 268.

10. Gogoi R. Musa nagensium var. Hongii Hkkinen-a new addition to the Flora of India. Taiwania. 2013:58:49-52.

11. Davey MW, Gudimella R, Harikrishna JA, Sin LW, Khalid N, Keulemans J. A draft Musa balbisiana genome sequence for molecular genetics in polyploid, inter- and intra-specific Musa hybrids. BMC Genomics. 2013;14: 683.

12. Jarret RL, Vuylsteke DR, Gawel NJ, Pimentel RB, Dunbar LJ. Detecting genetic diversity in diploid bananas using PCR and primers from a highly repetitive DNA sequence. Euphytica. 1993:68:69-76.

13. Lebot V, Aradhya KM, Manshardt R, Meilleur B. Genetic relationships among cultivated bananas and plantains from Asia and the Pacific. Euphytica. 1993; 67:163-75.

14. Ploetz RC. Assessing threats posed by destructive banana pathogens. In: III International symposium on banana: ISHS-ProMusa Symposium on Recent Advances in Banana Crop Protection for Sustainable, vol. 828; 2009. p. 245-

15. Gawel NJ, Jarret RL, Whittemore AP. Restriction fragment length polymorphism (RFLP)-based phylogenetic analysis of Musa. Theor Appl Genet. 1992;84:286-90

16. Venkatachalam L, Sreedhar RV, Bhagyalakshmi N. Genetic analyses of micropropagated and regenerated plantlets of banana as assessed by RAPD and ISSR markers. Vitr Cell Dev Biol Plant. 2007:43:267-74.

17. Fauré S, Noyer JL, Horry JP, Bakry F, Gonzàlez-de-León D, Lanaud C. A molecular marker based linkage map of diploid bananas (Musa acuminata). Theor Appl Genet. 1993;87:517-26.

18. D'Hont A, Paget GA, Escoute J, Carreel F. The interspecific genome structure of cultivated banana, Musa spp. revealed by genomic DNA in situ hybridization. Theor Appl Genet. 2000;100:177-83.

19. Damasco OP, Graham GC, Henry RJ, Adkins SW, Smiths MK, Godwin ID. Random amplified polymorphic DNA (RAPD) detection of dwarf off-types in micropropagated Cavendish (Musa spp. AAA) bananas. Plant Cell Rep. 1996; 16:118-23.

20. Crouch JH, Crouch HK, Tenkouano A, Ortiz R. VNTR-based diversity analysis of 2x and 4x full-sib Musa hybrids. Electron J Biotechnol. 1999;2:1-2. 
21. Umali RP, Kameya N, Nakamura I. Development of PCR-based fingerprinting tool in banana (Musa sp., AAA) and conversion of negative to positive DNA marker. HortScience. 2002;37:1108-11.

22. Nwakanma DC, Pillay M, Okoli BE. PCR-RFLP of the ribosomal DNA internal transcribed spacers (ITS) provides markers for the a and B genomes in Musa L. Theor Appl Genet. 2003;108:154-9.

23. Hebert PDN, Cywinska A, Ball SL, deWaard JR. Biological identifications through DNA barcodes. Proc Biol Sci. London. 2003;270:313-21.

24. Chen S, Yao H, Han J, Liu C, Song J, Shi L, et al. Validation of the ITS2 region as a novel DNA barcode for identifying medicinal plant species. PLoS One. United States. 2010;5:e8613.

25. Feng S, Jiang M, Shi Y, Jiao K, Shen C, Lu J, et al. Application of the ribosomal DNA ITS2 region of Physalis (Solanaceae): DNA barcoding and phylogenetic study. Front Plant Sci. 2016;7:1047.

26. Gutteridge A, Burns M. The application of DNA molecular approaches for the identification of herbal medicinal products. J Assoc Public Anal. 2013;41: 53-66.

27. Han J, Pang X, Liao B, Yao H, Song J, Chen S. An authenticity survey of herbal medicines from markets in China using DNA barcoding. Sci Rep. 2016;6:18723.

28. Shanmughanandhan D, Ragupathy S, Newmaster SG, Mohanasundaram S, Sathishkumar R. Estimating herbal product authentication and adulteration in India using a vouchered, DNA-based biological reference material library. Drug Saf. 2016;39:1211-27.

29. Hartvig I, Czako M, Kjær ED, Nielsen LR, Theilade I. The use of DNA barcoding in identification and conservation of rosewood (Dalbergia spp.). PLoS One. 2015;10:1-24.

30. Gismondi A, Leonardi D, Enei F, Canini A. Identification of plant remains in underwater archaeological areas by morphological analysis and DNA barcoding. Adv Anthropol. 2013;03:240-8

31. Elansary $H$, Ashfaq M, Ali HM, Yessoufou K. The first initiative of DNA barcoding of ornamental plants from Egypt and potential applications in horticulture industry. PLoS One. 2017;12:1-15.

32. Lahaye R, van der Bank M, Bogarin D, Warner J, Pupulin F, Gigot G, et al. DNA barcoding the floras of biodiversity hotspots. Proc Natl Acad Sci U S A. 2008;105:2923-8.

33. Jørgensen A, Stothard JR, Madsen H, Nalugwa A, Nyakaana S, Rollinson D. The ITS2 of the genus Bulinus: novel secondary structure among freshwater snails and potential new taxonomic markers. Acta Trop. 2013;128:218-25.

34. Gao T, Yao H, Song J, Liu C, Zhu Y, Ma X, et al. Identification of medicinal plants in the family Fabaceae using a potential DNA barcode ITS2. J Ethnopharmacol. 2010;130:116-21.

35. Yao H, Song J, Liu C, Luo K, Han J, Li Y, et al. Use of ITS2 region as the universal DNA barcode for plants and animals. PLoS One. 2010;5:1-9.

36. Gu W, Song J, Cao Y, Sun Q, Yao H, Wu Q, et al. Application of the ITS2 region for barcoding medicinal plants of Selaginellaceae in Pteridophyta. PLoS One. 2013:8:1-8.

37. Lee SC, Wang CH, Yen CE, Chang C. DNA barcode and identification of the varieties and provenances of Taiwan's domestic and imported made teas using ribosomal internal transcribed spacer 2 sequences. J Food Drug Anal. 2017:25:260-74

38. Ragupathy S, Dhivya S, Patel K, Sritharan A, Sambandan K, Gartaula H, et al. DNA record of some traditional small millet landraces in India and Nepal. 3. Biotech. 2016:6:133.

39. De Jesus ON. E Silva SD, Amorim EP, Ferreira CF, de Campos JMS, Silva G de $\mathrm{G}$, et al. genetic diversity and population structure of Musa accessions in ex situconservation. BMC Plant Biol. 2013;13:41.

40. Bhat KV, Jarret RL, Rana RS. DNA profiling of banana and plantain cultivars using random amplified polymorphic DNA (RAPD) and restriction fragment length polymorphism (RFLP) markers. Electrophoresis. 1995;16:1736-45.

41. Afanador-Kafuri L, Minz D, Maymon M, Freeman S. Characterization of Colletotrichum isolates from tamarillo, passiflora, and mango in Colombia and identification of a unique species from the genus. Phytopathol. 2003;93: 579-7.

42. Castro C, Hernandez A, Alvarado L, Flores D, Adcrs A, Rica C, et al. DNA Barcodes in Fig Cultivars (Ficus carica L .) Using ITS Regions of Ribosomal DNA, the psbA-trnH Spacer and the matK Coding Sequence. Am J Plant Sci. 2015;6:95-102

43. Galbacs ZS, Molnar S, Halasz G, Kozma P, Hoffmann S, Kovacs L, et al. Identification of grapevine cultivars using microsatelite-based DNA barcodes. Vitis. 2015:48:17-24.
44. Hidayat T, Abdullah FI, Kuppusamy C, Samad AA, Wagiran A. Molecular identification of Malaysian pineapple cultivar based on internal transcribed spacer region. APCBEE Procedia. 2012;4:146-51.

45. Wu B, Zhong G, Yue J, Yang R, Li C, Li Y, et al. Identification of Pummelo cultivars by using a panel of 25 selected SNPs and 12 DNA segments. PLoS One. 2014;9:1-12.

46. Javed MA, Chai MK, Othman RY. Morphological characterization of malaysian wild banana. Biotropia. 2002;1:21-37.

47. Hapsari L, Lestari DA. Fruit characteristic and nutrient values of four Indonesian banana cultivars (Musa spp.) at different genomic groups. Agrivita. 2016:38:303-11.

48. Hřibová E, Čížková J, Christelová P, Taudien S, de Langhe E, Doležel J. The ITS1-5.8S-ITS2 sequence region in the Musaceae: structure, diversity and use in molecular phylogeny. PLoS One. 2011;6:1-11.

49. Simmonds NW. The evolution of the bananas; 1962.

50. Tripathi AM, Tyagi A, Kumar A, et al. The internal transcribed spacer (ITS) region and $\mathrm{trnH}$-psbA are suitable candidate loci for DNA barcoding of tropical tree species of India. PLoS One. 2013;8(2):e57934.

51. White TJ, Bruns T, Lee S, Taylor J. Amplification and direct sequencing of fungal ribosomal RNA genes for phylogenetics. PCR Protoc. 1990;18:315-22.

52. Tamura K, Dudley J, Nei M, Kumar S. Molecular evolutionary genetics analysis (MEGA) software version 4.0. Mol Biol Evol. 2007;24:1596-9.

53. Thompson JD, Gibson TJ, Higgins DG. Multiple sequence alignment using ClustalW and ClustalX. Curr Protoc Bioinforma. 2003:1:2-3.

54. Meyer CP, Paulay G. DNA barcoding: error rates based on comprehensive sampling. PLoS Biol. 2005:3:e422.

55. Selvaraj D, Sarma RK, Shanmughanandhan D, Srinivasan R, Ramalingam S. Evaluation of DNA barcode candidates for the discrimination of the large plant family Apocynaceae. Plant Syst Evol. 2015;301:1263-73.

56. Ross HA, Murugan S, Li WLS. Testing the reliability of genetic methods of species identification via simulation. Syst Biol England. 2008;57:216-30.

57. Kimura M. A simple method for estimating evolutionary rates of base substitutions through comparative studies of nucleotide sequences. J Mol Evol. 1980;16:111-20

58. Tajima F. Evolutionary relationship of DNA sequences in finite populations. Genetics. 1983;105:437-60.

59. Watterson GA. On the number of segregating sites in genetical models without recombination. Theor Popul Biol. 1975;7:256-76.

60. Tajima F. Statistical method for testing the neutral mutation hypothesis by DNA polymorphism. Genetics. United States. 1989;123:585-95.

\section{Publisher's Note}

Springer Nature remains neutral with regard to jurisdictional claims in published maps and institutional affiliations.

Ready to submit your research? Choose BMC and benefit from:

- fast, convenient online submission

- thorough peer review by experienced researchers in your field

- rapid publication on acceptance

- support for research data, including large and complex data types

- gold Open Access which fosters wider collaboration and increased citations

- maximum visibility for your research: over $100 \mathrm{M}$ website views per year

At $\mathrm{BMC}$, research is always in progress.

Learn more biomedcentral.com/submissions 